\title{
VIDEO ANIMASI 2D INFOGRAFIS APLIKASI LAKSA \\ ( LAYANAN ASPIRASI KOTAK SARAN ANDA ) \\ PADA DINAS KOMUNIKASI DAN INFORMASI \\ (KOMINFO) PEMERINTAHAN \\ KOTA TANGERANG
}

\author{
Lusyani Sunarya ${ }^{1}$, Allyufi Fazril Rasyidin ${ }^{2}$, Deka Witara ${ }^{3}$ \\ ${ }^{1}$ Dosen STMIK Raharja \\ ${ }^{2,3}$ Mahasiswa STMIK Raharja \\ 1,2,3 J1.Jendral Sudirman No.40,modern,Tangerang,021-5529692
}

Email : lusyani@,raharja.info, allyufi@raharja.info, deka@raharja.info

\begin{abstract}
The development of information and communication today is very important for the wider community. This is evidenced by the many pioneers of telecommunications and information which serves to realize the information and communication, either through print media such as newspapers, magazines, books, and electronic media such as radio, television, telephone, and internet. Currently the Department of Communication and Information Technology, provide services or means of media information through some form of media in the form of social media and websites that in a sense is still not enough to meet the information needs effective services. In order to convey the latest information more effective services should at least have the means of media that can support the effectiveness of the communication process performed by an institution or agency. LAKSA application is a communication medium that serves to continue the public complaints that go through Call Center so that it can respond rapidly, so that people can easily give a message, complaints, suggestions, or report to the Office of Tangerang City Government. The methodology used in this study include problem analysis methods, data collection methods, methods of analysis of the design and method of production concept mavib (KPM) which includes: pre-production, production and post production. Thus in this research is intended to make the media infographic form of $2 D$ animation, namely Design Video Animation Infographic Applications LAKSA (Report Aspiration Suggestion Box you) at the Department of Communications and Informatics of Tangerang, so that through the design of the media is expected to provide forms of information services more attractive, effective, and easily accepted, especially by the people of Tangerang.
\end{abstract}

Key words : Video, Animation, Infographic

\begin{abstract}
ABSTRAKSI
Perkembangan informasi dan komunikasi saat ini sangat berperan penting bagi masyarakat luas. Hal ini dibuktikan dengan banyaknya pelopor telekomunikasi dan informasi yang menyajikan dengan merealisasikan informasi dan komunikasi, baik melalui media cetak seperti koran, majalah, buku, maupun media elektronik seperti radio, televisi, telepon, dan internet. Saat ini Dinas Kominfo, memberikan layanan atau sarana media informasi melalui beberapa bentuk media yaitu berupa media sosial maupun website yang di rasa masih belum cukup untuk memenuhi kebutuhan informasi pelayanan yang efektif. Agar dapat menyampaikan informasi pelayanan terbaru yang
\end{abstract}


lebih efektif setidaknya harus mempunyai sarana media yang dapat menunjang efektivitas dalam proses komunikasi yang dilakukan oleh suatu lembaga atau instansi. Aplikasi LAKSA adalah media komunikasi yang berfungsi untuk meneruskan keluhan masyarakat yang masuk melalui Call Center sehingga dapat direspon dengan cepat, sehingga masyarakat dapat dengan mudah memberikan pesan, keluhan, saran, ataupun laporan kepada Dinas Pemerintahan Kota Tangerang. Adapun metodologi yang digunakan dalam penelitian ini diantaranya metode analisa permasalahan, metode pengumpulan data, metode analisa perancangan dan metode konsep produksi mavib (KPM) yang meliputi : pre production, production, dan post production. Dengan demikian pada penelitian ini bermaksud untuk membuat media infographic berupa animasi 2D yaitu Perancangan Video Animasi Infographic Aplikasi LAKSA (Laporan Aspirasi Kotak Saran Anda) pada Dinas Kominfo Kota Tangerang, sehingga melalui perancangan media tersebut diharapkan dapat memberikan bentuk informasi pelayanan yang lebih menarik, efektif, serta mudah diterima khususnya oleh masyarakat Kota Tangerang.

Kata kunci: Video, Animasi, Infographic

\section{PENDAHULUAN}

Pesatnya perkembangan informasi dan komunikasi saat ini sangat berperan penting bagi masyarakat luas. Hal ini dibuktikan dengan banyaknya pelopor telekomunikasi dan informasi yang berlomba - lomba menyajikan dengan merealisasikan informasi dan komunikasi yang dapat digunakan untuk memperoleh informasi, baik melalui media cetak seperti koran, majalah, buku, maupun media elektronik seperti radio, televisi, telepon, dan internet.

Dinas Kominfo adalah suatu lembaga instansi pemerintahan yang membidangi pengolahan data informasi dan komunikasi yang dibutuhkan oleh Pemerintahan Kota Tangerang. Adapun lembaga tersebut terletak di Gedung Pusat Pemerintahan Lt.4 yang beralamatkan di Jl.Satria Sudirman Kota Tangerang. Lembaga ini dipimpin oleh seorang kepala dinas, serta terdapat satu sekretariat dan tiga bidang, diantaranya : bidang pengolahan data dan desiminasi informasi, bidang pos dan telekomunikasi, dan bidang telematika. Lembaga ini dibentuk pada tahun 2008, berdasarkan Peraturan Walikota Tangerang Nomor 28 tahun 2008 Tentang Organisasi dan Tata Kerja Dinas Informasi dan Komunikasi.

Saat ini Dinas Kominfo, memberikan layanan atau sarana media informasi melalui beberapa bentuk media yaitu berupa media sosial maupun website, dan media informasi sendiri saat ini memiliki perkembangan yang sangat pesat dibandingkan dengan media komunikasi lainnya, kebutuhan mengenai informasi akan terus bertambah sesuai perkembangan zaman, agar dapat menyampaikan informasi pelayanan terbaru yang lebih efektif setidaknya harus mempunyai sarana media yang dapat menunjang efektivitas dalam proses komunikasi yang dilakukan oleh suatu lembaga atau instansi. Pelayanan baru yang diluncurkan oleh pemerintah Kota Tangerang bernama LAKSA (Laporan Aspirasi Kotak Saran Anda), aplikasi LAKSA adalah media komunikasi yang berfungsi untuk meneruskan keluhan masyarakat yang masuk melalui Call Center. sehingga dapat direspon dengan cepat oleh dinas terkait, sehingga masyarakat dapat dengan mudah memberikan pesan, keluhan, saran, ataupun laporan kepada Dinas Pemerintahan Kota Tangerang, dengan demikian penulis tertarik untuk membuat media infographic berupa animasi 2D yaitu Video Animasi Infographic Aplikasi LAKSA 
(Laporan Aspirasi Kotak Saran Anda) pada Dinas Kominfo Kota Tangerang. Sehingga melalui perancangan media tersebut diharapkan dapat memberikan bentuk informasi pelayanan yang lebih menarik, efektif, serta mudah diterima khususnya oleh masyarakat Kota Tangerang.

Dari hasil analisa kebutuhan yang dilakukan penulis terhadap Dinas Kominfo, membutuhkan media informasi yang menarik untuk memudahkan masyarakat dalam memberikan pesan, keluhan, saran, ataupun laporan kepada Dinas Pemerintahan Kota Tangerang melalui media infographic berupa video animasi 2D .

\section{PERMASALAHAN}

Saat ini Dinas Kominfo, memberikan layanan atau sarana media informasi melalui media sosial dan website Kota Tangerang, media informasi sendiri saat ini memiliki perkembangan yang sangat pesat dibandingkan dengan media komunikasi lainnya, dan kebutuhan informasi terus bertambah sesuai perkembangan zaman. Agar dapat menyampaikan informasi pelayanan terbaru, mengenai aplikasi LAKSA (Layanan Aspirasi Kotak Saran Anda) yang lebih efektif sebagai media komunikasi yang berfungsi untuk meneruskan keluhan masyarakat yang masuk melalui Call Center, dan dapat direspon dengan cepat oleh dinas terkait, sehingga masyarakat dapat dengan mudah memberikan pesan, keluhan, saran, ataupun laporan kepada Dinas Pemerintahan Kota Tangerang, setidaknya harus mempunyai sarana media yang dapat menunjang efektivitas dalam proses komunikasi yang dilakukan oleh suatu lembaga atau instansi yaitu dalam bentuk Video Animasi 2D Infografis Aplikasi LAKSA (Layanan Aspirasi Kotak Saran Anda).

\section{LANDASAN TEORI}

\section{Definisi Perancangan}

Perancangan adalah setiap rancangan harus memenuhi kebutuhan penggunanya dan dapat berfungsi dengan baik, fungsi timbul sebagai akibat dari adanya kebutuhan manusia dalam usaha untuk mempertahankan serta mengembangkan hidup dan kehidupannya di alam semesta ini ${ }^{[9]}$.

Perancangan adalah tahap pembuatan spesifikasi mengenai arsitektur program, gaya, tampilan, dan kebutuhan material atau bahan untuk program. Tahap ini biasanya menggunakan storyboard untuk menggambarkan deskripsi tiap scene lain dan bagian alur (flowchart) untuk menggambarkan aliran dari satu scene ke scene lain ${ }^{[2]}$.

\section{Pengertian Media}

Media adalah segala bentuk yang digunakan untuk menyalurkan informasi. Pengertian media yang diberikan AECT (Association for education communication and tecnology) ini menunjukkan bahwa istilah "media" memiliki makna yang sangat umum $^{[3]}$.

Media adalah sarana untuk menyampaikan pesan atau informasi kepada publik dengan menggunakan berbagai unsur komunikasi grafis seperti teks atau gambar atau foto $^{[11]}$. 


\section{Definisi Grafis}

Desain yang menekankan tanpa keindahan akan tidak menarik, sehingga tidak komunikatif. Menarik atau indah bisa dilihat dengan menggunakan mata (lahir) atau dengan hati (batin), maka desain akan menarik apabila indah dipandang atau konsepnya yang kreatif. Keindahan yang dibahas disini lebih ditekankan pada kemampuan mata sebagai penilai ${ }^{[13]}$.

\section{Pengertian Video}

Video merupakan penggabungan gambar-gambar mati yang dibaca secara berurutan dalam suatu waktu atau kecepatan tertentu. Gambar-gambar yang digabung tersebut dinamakan frame dan kecepatan pembacaan gambar disebut dengan frame rate, dengan satuan fps (frame per second). Karena di mainkan dalam kecepatan yang tinggi maka tercipta ilusi gerak yang halus, semakin besar nilai frame rate maka akan semakin halus pergerakan yang ditampilkan ${ }^{[1]}$.

\section{Video Infografis}

Infographics singkatan dari "information graphic". Istilah ini telah mendapatkan popularitas baru-baru ini didasarkan pada peningkatan penggunaan grafis dalam pemasaran online. Beberapa menggunakan istilah ini untuk berkonotasi format unik yang telah diadopsi secara luas untuk aplikasi ini, yang ditandai dengan illustrasi, tipografi, dan orientasi vertikal yang menampilkan bermacam-macam fakta ${ }^{[7]}$.

\section{Aplikasi LAKSA (Layanan Aspirasi Kotak Saran Anda)}

LAKSA (Layanan Aspirasi Kotak Saran Anda) adalah media komunikasi yang berfungsi untuk meneruskan keluhan masyarakat yang masuk melalui call center sehingga dapat direspon dengan cepat oleh Dinas terkait. ${ }^{[14]}$

\section{Animasi}

Animasi adalah gambar bergerak terbentuk dari sekumpulan objek (gambar) yang disusun secara beraturan mengikuti alur pergerakan yang telah ditentukan pada setiap pertambahan hitungan waktu yang terjadi. Gambar tersebut dapat berupa gambar makhluk hidup, benda mati, ataupun tulisan.

Animasi berasal dari bahasa inggris yaitu animate yang artinya menghidupkan, memberi jiwa, dan menggerakan benda mati. Animasi merupakan proses membuat objek yang asalnya objek mati, kemudian disusun dalam posisi yang berbeda seolah menjadi hidup. Di dalam animasi ada dua objek penting, yaitu objek atau gambar dan alur gerak.

Animasi secara umum dapat dikatakan sebagai sequence gambar yang ditampilkan pada tenggang waktu (timeline) tertentu sehingga tercipta sebuah ilusi gambar bergerak.

Prinsip dasar animasi ditemukan dari karakter mata manusia yaitu : persistance of vision (pola penglihatan yang teratur). Paul Roget, Joseph Plateau, dan Pierre Desvigenes, dengan alat optik yang mereka ciptakan, berhasil membuktikan bahwa mata manusia cenderung menangkap urutan gambar-gambar pada tenggang waktu tertentu sebagai sebuah pola ${ }^{[3]}$. 


\section{LITERATURE REVIEW}

Berdasarkan studi pustaka pada beberapa penelitian, maka penulis melakukan literature review terhadap penelitian-penelitian sebelumnya yaitu sebagai berikut :

1. Penelitian Muhamd Riyan Surya Nugraha dengan judul Perancangan Media Video Infografis Menggunakan Animasi 3D Max Di Klinik Usada Nugraha Kabupaten Tangerang (2013).

Media penunjang informasi dan promosi sangat penting dalam membangun image dari sebuah lembaga atau institusi, salah satunya adalah media video promosi. Fungsi media video promosi secara umum adalah selain sebagai aset perusahaan juga berfungsi sebagai tanda atau identitas dari perusahaan dalam menjalin kerjasama dengan relasi yang baik dengan perusahaan atau lembaga dan instansi terkait lainnya. Penelitian ini bertujuan untuk menerapkan konsep media desain, dapat memberikan informasi dan promosi yang lebih efektif mengenai profil dan aktivitas perusahaan. ${ }^{[8]}$

2. Menurut jurnal yang disusun oleh Ikhwan August Star Hanif, Andry Alamsyah, dan Yahya Peranginangin dengan judul Perancangan Infografis Sebagai Alternatif Bentuk Nilai Mahasiswa (Studi Pada Mata Kuliah di Telkom University, Eksperimen: Mata Kuliah Entrepreneurship Prodi Adbis) (2013).

Penilaian hasil pembelajaran mahasiswa adalah hal yang biasa dilakukan oleh seorang dosen atau staf pengajar. Nilai tersebut menjadi ukuran keberhasilan mahasiswa dalam mengikuti pembelajaran suatu mata kuliah baik di dalam kelas maupun diluar kelas. Pada umumnya bentuk dari nilai adalah data statistik yang ditampilkan dalam bentuk tabel. Nilai mata kuliah di Telkom University ditunjukan dengan standar nilai A, AB, B, BC, C, D, E, dan T. Nilai tersebut seringkali berupa data statistik. Maka diperlukan merubahnya menjadi visual, dalam hal ini berbentuk infografis dengan memilih mata kuliah eksperimen Entrepreneurship Prodi Administrasi Bisnis, Fakultas Komunikasi Bisnis, Telkom University. MOOC (Masive Open Online Course) merupakan metode pembelajaran online yang mengandalkan konten digital sebagai media pembelajaran. Jumlah user atau pelajar pada MOOC bisa mencapai ratusan, ribuan, hingga ratusan ribu. Jumlah yang banyak ini akan membutuhkan manajemen konten yang optimal. ${ }^{[4]}$

3. Menurut jurnal yang di susun oleh Mulyate dan Karenia Marisa dengan judul Perancangan Buku Kumpulan Infografis Resep Aneka Hidangan Pembuka dan Penutup Ala Barat Untuk Anak-Anak (2013)

Perancangan ini membuat buku berisi kumpulan infografis resep aneka hidangan pembuka dan penutup ala Barat, disajikan dengan visual yang menarik yang sedapat mungkin disesuaikan dengan karakter anak-anak. Dengan adanya buku ini diharapkan mampu meningkatkan minat membaca anak-anak di Indonesia serta membantu meningkatkan kreativitas dan kemampuan mereka dalam memasak. $^{[12]}$ 
4. Penelitian Doni Indriasto dengan judul Perancangan Infografis Board Game Edukasi Sejarang Perang Surabaya 10 November 1945 (2014)

Berawal dari fenomena dimana sejarah yang telah dilupakan menyebabkan kurangnya pengetahuan tentang peristiwa maupun perjuangan. Rasa Nasionalisme mulai menipis seiring berjalannya era globalisasi contohnya produk permainan. Dibutuhkan metode baru dalam pengajaran sejarah yang dapat menarik minat anak-anak dalam memainkan dan memahami. Dalam board game ini akan di hadirkan tempat-tempat sejarah dan tokoh pahlawan sebagai edukasi dari permainan, yang dibagi dalam dua kartu yaitu pertanyaan dan infografis mengenai perang 10 November 1945. Konsep utama dalam perancangan board game ini adalah "Experience Heroic Surabaya", pengalaman yang disampaikan melalui perjuangan mulai dari start sampai finish dengan cara menjawab pertanyaan untuk bisa lanjut. Menggunakan ilustrasi yang lucu dan menarik yang akan memberikan kejutan setiap membuka kemasan karena ada pop-up environment-nya mengenai gedung perjuangan. ${ }^{[5]}$

\section{METODOLOGI PENELITIAN}

Metode penelitian yang dilakukan, dalam merancang Video Animasi 2D Infografis Aplikasi LAKSA adalah sebagai berikut : (1) Metode Analisa Permasalahan didapatkan dari hasil interview yang dilakukan dengan stakeholder pada Dinas KOMINFO Kota Tangerang. (2) Metode Pengumpulan Data dilakukan dengan cara Observasi, Interview, dan Studi Pustaka. (3) Metode Analisa Perancangan Media. Media Indographic Animasi 2D yang dibutuhkan oleh Dinas Kominfo Kota Tangerang, akan diproduksi dengan menggunakan aplikasi program komputer grafis diantaranya : Adobe Premiere Pro CS 3, Adobe After Effects CS 3, dan Adobe Photoshop CS 3. (4) Metode Konsep Produksi Mavib (KPM) yang meliputi : Pre Production, Production, dan Post Production.

\section{PEMBAHASAN}

Merancang sebuah media audio visual khususnya video animasi 2D tentang aplikasi LAKSA (Layanan Aspirasi Kotak Saran Anda), perlu dilakukan beberapa tahapan di dalam Konsep Produksi Media (KPM), adapun tahapan yang perlu dilakukan yaitu Preproduction, Production, dan Postproduction.

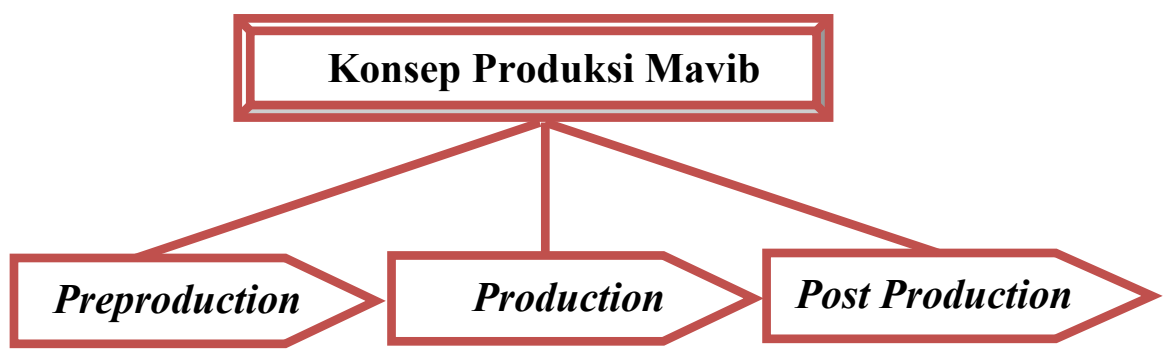

Gambar 1. Konsep Produksi Media 


\section{Preproduction}

Ada beberapa langkah Preproduction dalam pembuatan Video Animasi 2D Infografis Aplikasi LAKSA (Layanan Aspirasi Kotak Saran Anda), dimulai dari observasi lapangan dengan mengumpulkan data-data yang diperlukan, kemudian dituangkan dalam sebuah ide/gagasan secara sistematis, agar dapat menghasilkan video Infografis yang menarik dan informatif yang di tunjukkan pada masyarakat Kota Tangerang, yang dilengkapi dengan pembuatan sinopsis, script writting dan storyboard. Dua tahapan terakhir adalah pemilihan dubbing. Semua tahapan yang ada harus sesuai time schedule yang di tetapkan. Untuk lebih jelasnya di ilustrasikan pada bagan berikut ini :

\section{PREPRODUCTION}

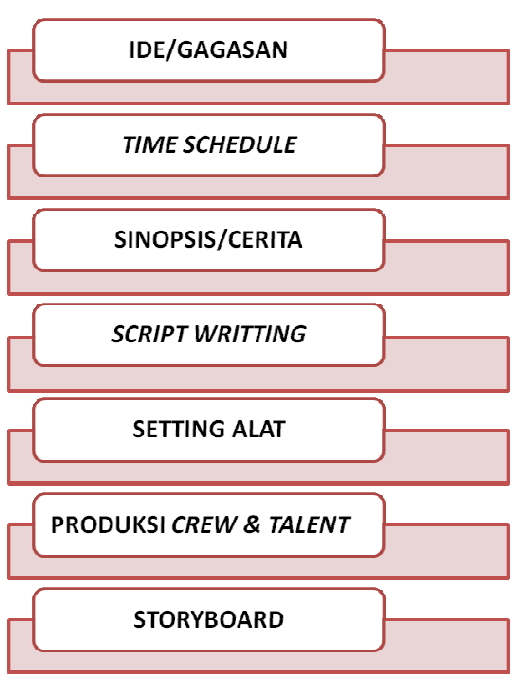

Gambar 2. Prepoduction

\section{Observasi}

Pengamatan yang dilakukan pada Dinas KOMINFO Kota Tangerang, mengenai sudah ada atau tidaknya video infografis, di setiap layanan yang telah di rancang untuk Kota Tangerang.

Ide

Dinas Kominfo Kota Tangerang ingin meningkatkan penyampaian informasi mengenai layanan aplikasi terbaru yaitu LAKSA (Layanan Aspirasi Kotak Saran Anda). Media Video Infografis merupakan media yang sangat efektif untuk memberikan penyampaian informasi berupa media audio visual berbasis animasi 2D, sehingga dapat menarik dan memudahkan masyarakat Kota Tangerang dalam memberikan pesan, keluhan, saran, ataupun laporan kepada Dinas Pemerintahan Kota Tangerang, sehingga dapat menunjang efektivitas dalam proses komunikasi. 


\section{Sinopsis}

"Memperkenalkan tampilan Kota Tangerang mulai dari taman cikokol, gedung pusat pemerintahan Kota Tangerang, masjid al azhom, dan bus APTB yang melewati kawasan Kota Tangerang. lalu menampilkan gambaran contoh media sosial yang mengeluhkan dan mengkritik ataupun bertanya kepada pemerintah Kota Tangerang melalui \#PelayananKotaTangerang. Setelah itu muncul tokoh pegawai PNS yang merasa hal ini harus di perbaiki, maka pegawai tersebut memberikan solusi baru yaitu aplikasi LAKSA (Layanan Aspirasi Kotak Saran Anda) juga setelah itu memberikan penjelasan mengenai layanan LAKSA. Selanjutnya menampilkan bagaimana caranya menggunakan aplikasi tersebut, lalu memberikan informasi bahwa ada 2 cara untuk menggunakan layanan tersebut melalui Telepon dan SMS. Setelah itu menampilkan susunan cara penggunaan aplikasi LAKSA dari via Telepon maupun Via SMS. Lalu setiap keluhan tersebut akan di tampilkan di website kota tangerang”.

\section{Storyboard}

Storyboard adalah sebuah gambar sket yang dilengkapi dengan petunjuk atau catatan pengambilan gambar sekaligus gerak pada sebuah karakter untuk kebutuhan pembuatan animasi. Selama proses preproduction, perencanaan yang berhubungan dengan visualiasasi yang akan dibuat membutuhkan storyboard sebagai media bantuannya. Adapun storyboard dalam Video Animasi 2D Infografis Aplikasi LAKSA (Layanan Aspirasi Kotak Saran Anda) Pada Dinas Komunikasi dan Informasi (KOMINFO) Pemerintahan Kota Tangerang adalah sebagai berikut :

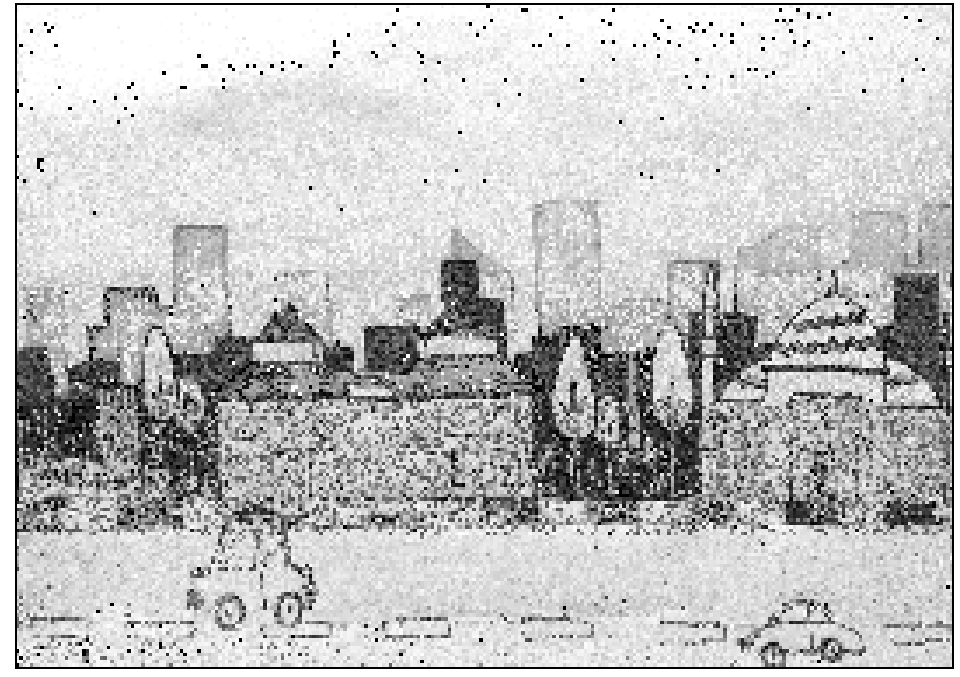

Gambar 3.

Scene 1 Menampilkan suasana Kota Tangerang 


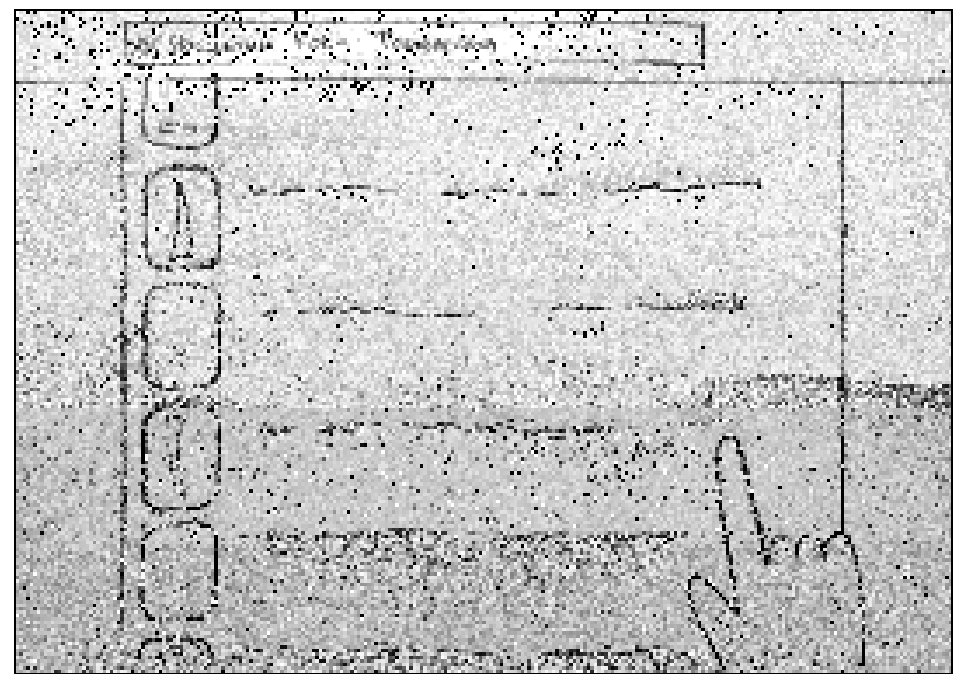

Gambar 4.

Scene 2 Menampilkan contoh media sosial

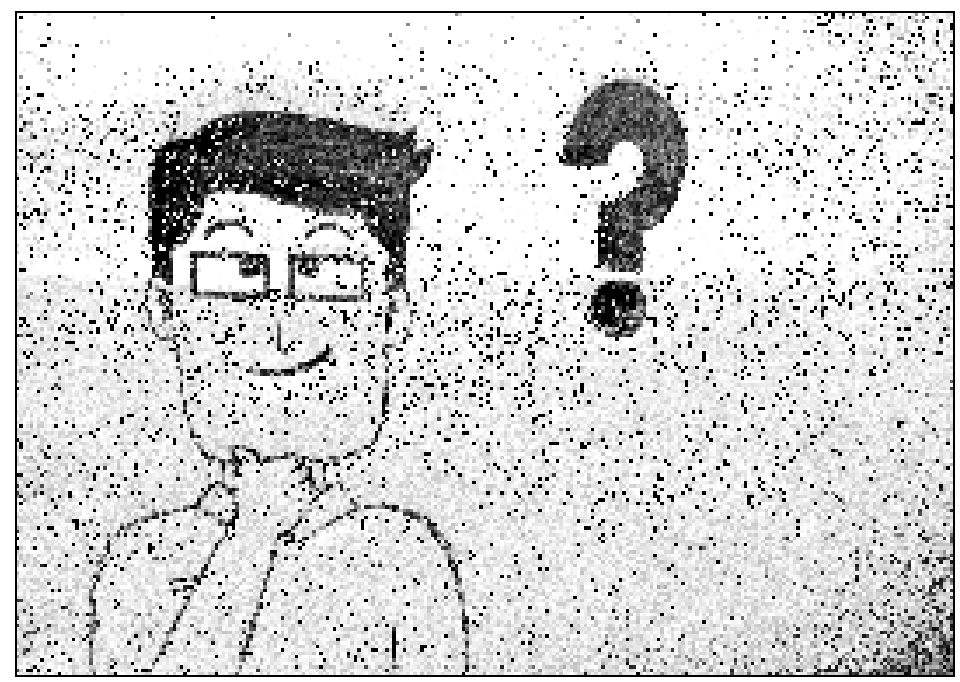

gambar 5.

Scene 3 menampilkan pegawai pns yang sedang berfikir

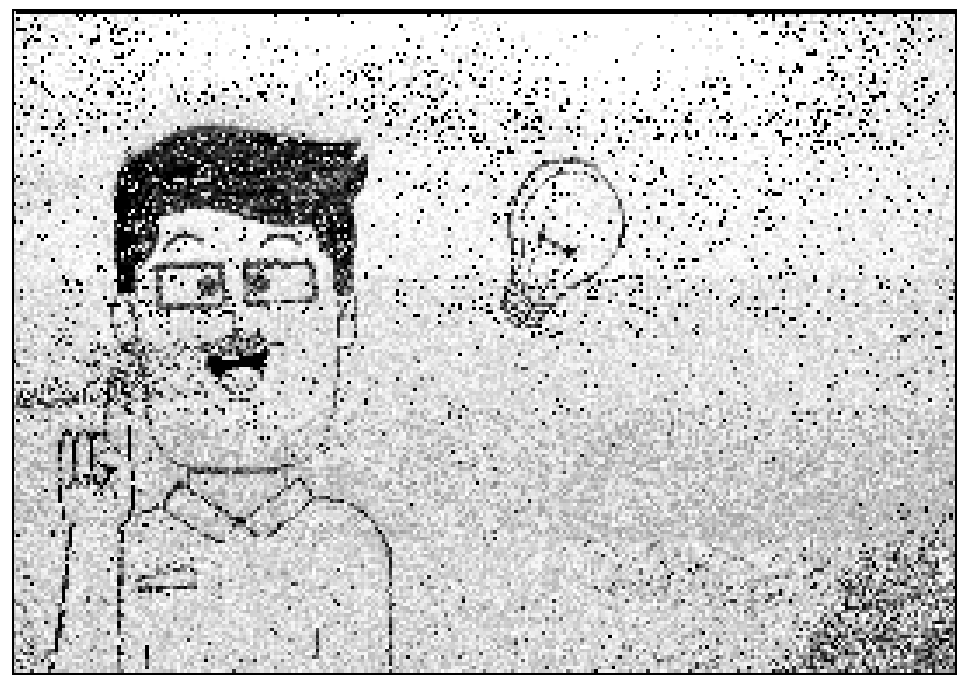

Gambar 6.

Scene 4 Menampilkan pegawai PNS yang mendapatkan solusi 


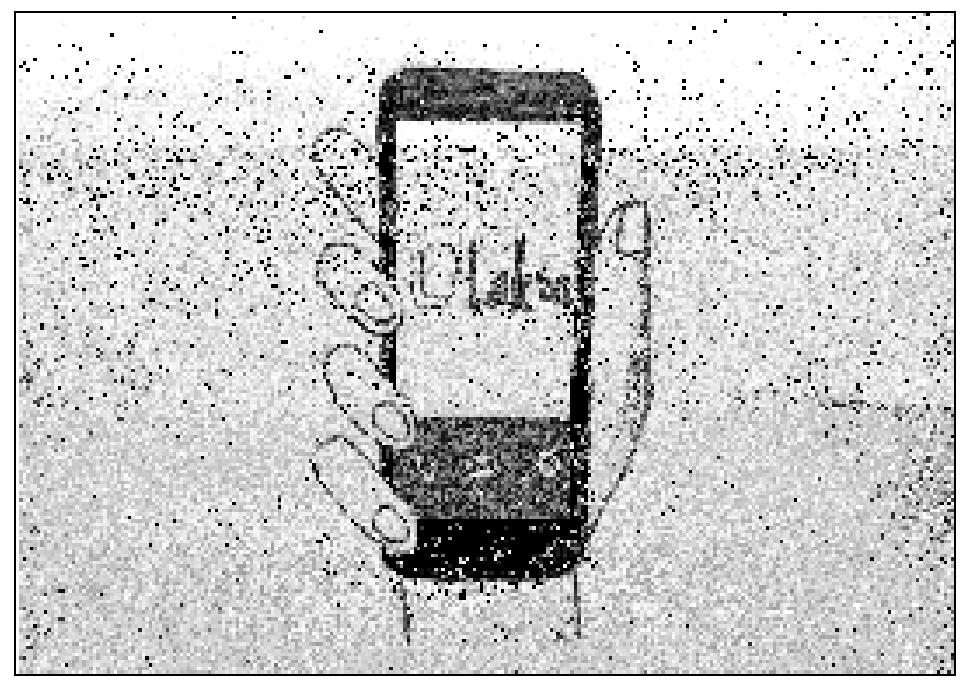

Gambar 7.

Scene 5 Menampilakan logo aplikasi LAKSA melaui ponsel

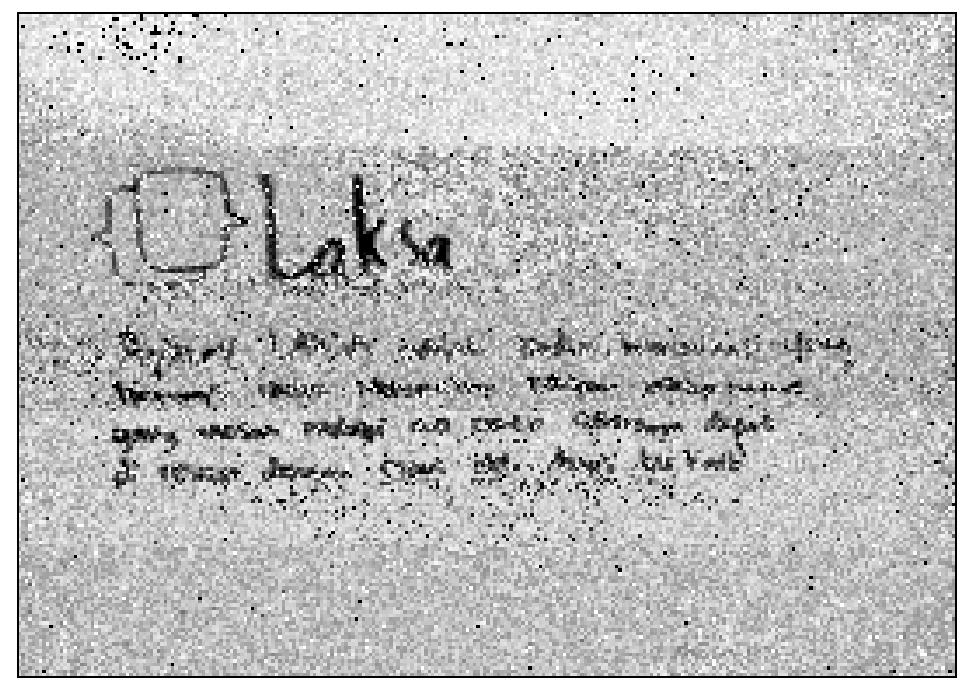

Gambar 8.

Scene 6 Menampilkan dan menjelaskan layanan LAKSA

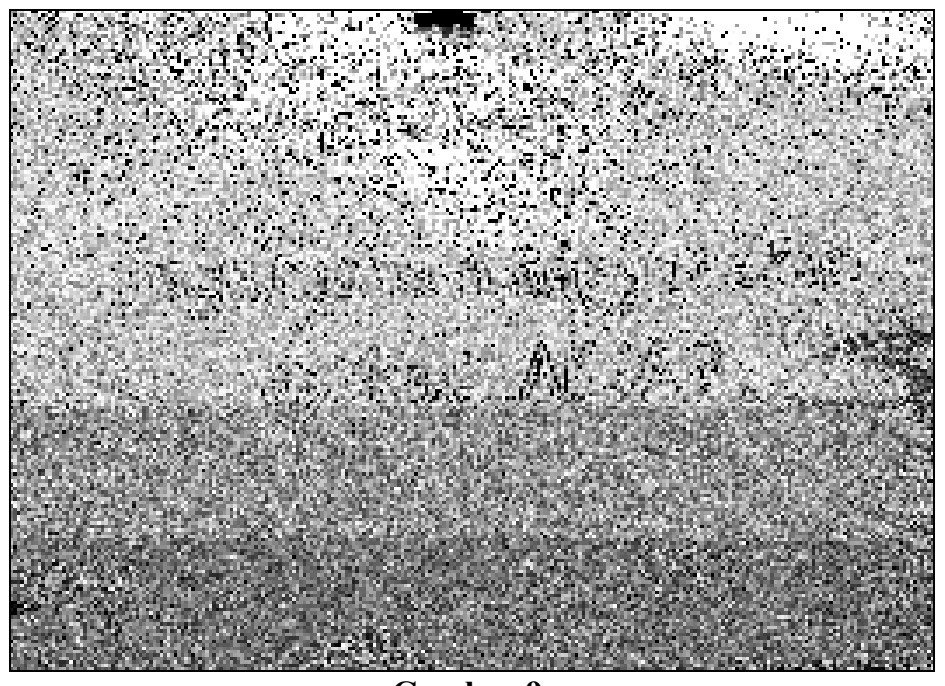

Gambar 9.

Scene 7 Menampilkan menggunakan layanan LAKSA 


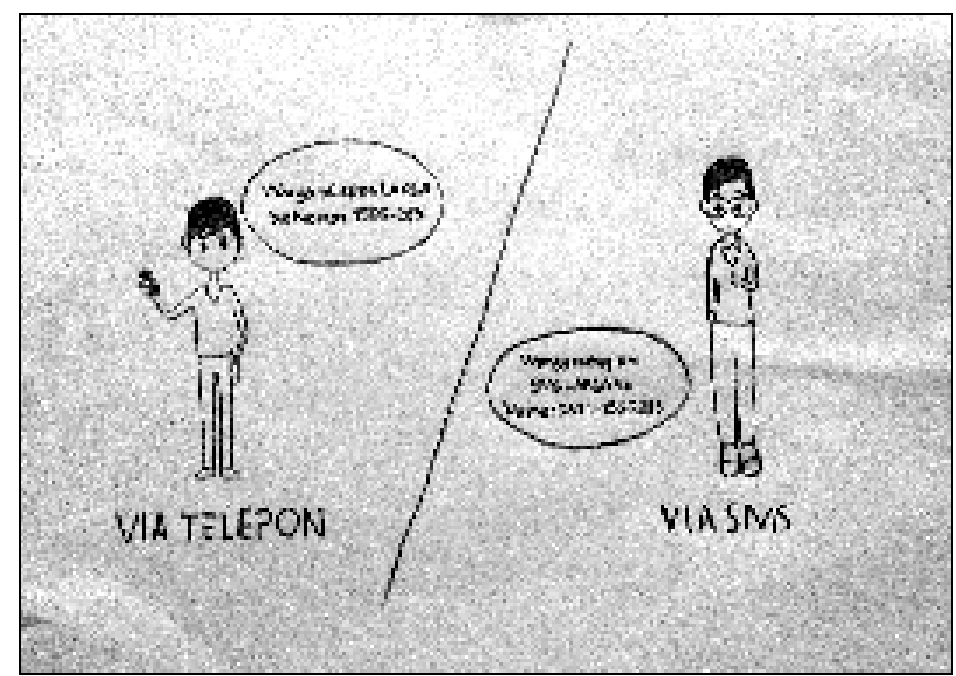

Gambar 10.

Scene 8 Cara menggunakan aplikasi LAKSA

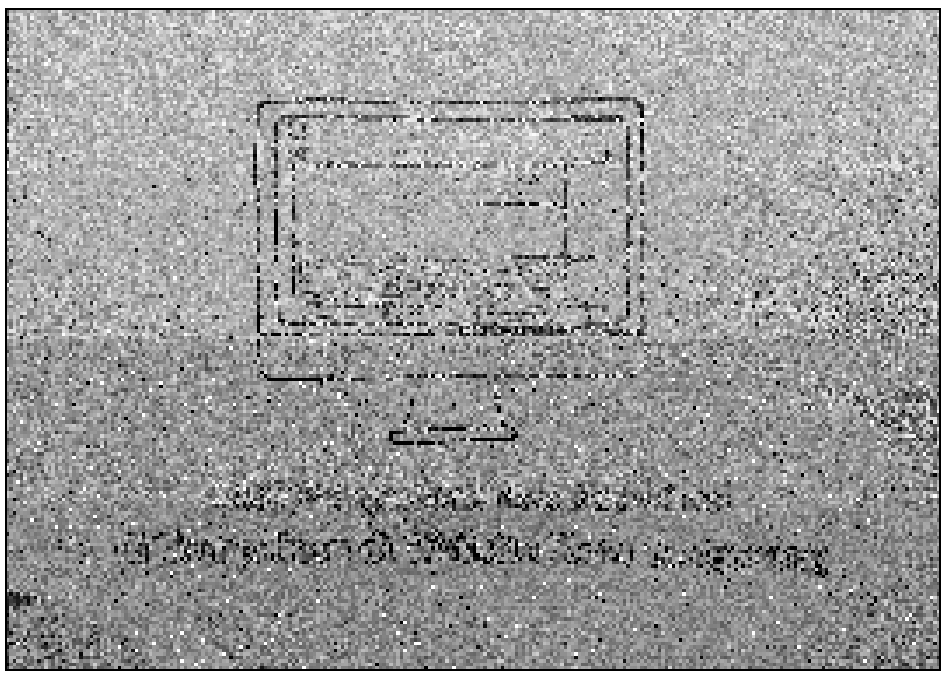

Gambar 11.

Scene 9 SMS pengaduan di tampilkan di website

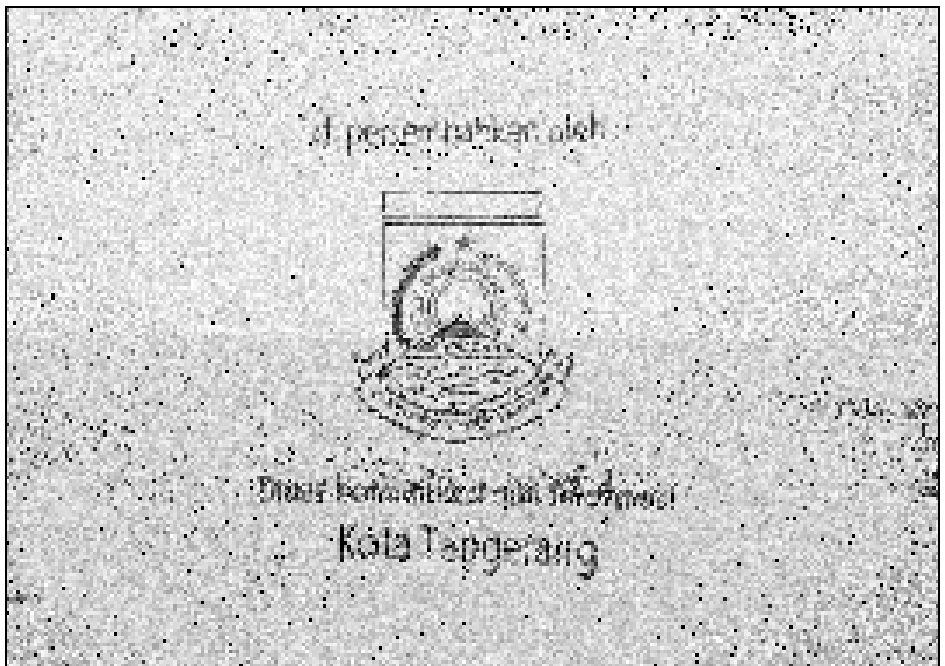

Gambar 12.

Scene 10 Penutup 


\section{Design}

Design adalah dengan membuat visualisasi dalam bentuk vector 2D. Dalam media infographic aplikasi LAKSA ini disesuaikan dengan storyboard yang dirancang sebagai acuan dari setiap scene yang dibuat. Perancangan design ini sangatlah penting agar tampilan animasi terlihat lebih menarik audience, dalam tahap design ini perlu memperhatikan design, layout, serta komposisi dari setiap scene yang dirancang, dimulai dari sketsa pensil, lalu di design ke dalam bentuk vector dan di gerakkan seperti film animasi 2D.

\section{Production}

Production adalah tahapan dimana pengambilan gambar atau shooting dilakukan. Dalam production pada tahapan project ini dibagi menjadi :

a. Perencanaan multimedia diperlukan tiga tahapan elemen sitematis yaitu teks, gambar, dan suara kemudian digabungkan atau di kombinasikan menjadi satu file yang berbentuk video. Perencanaan multimedia ini di dasarkan atas konsep yang efektif untuk menjangkau masyarakat dalam memperoleh informasi secara akurat dan efisien.

b. Perancangan audio sangat berperan penting dalam penyampaian informasi dalam bentuk suara. Jika tidak ada suara ataupun audio, video yang dibawakan atau di putar menjadi kurang memuaskan dan cepat bosan. Karena jika tidak ada audio maka langkah yang di tempuh adalah dengan memperbanyak tulisan, dan hal ini yang membuat tampilan video jadi membosankan. Dalam konsep produksi ini audio memiliki tujuan audio, strategi audio dan program audio.

c. Perencanaan visual yang dihasilkan adalah keseluruhan penggabungan dari gambar, suara, dan teks yang menghasilkan satu video utuh yang digunakan untuk memberikan informasi. Dengan menggabungkan teks dengan format penulisan yang telah ditentukan, gambar yang telah di produksi sebelumnya dan suara yang di hasilkan dari membaca naskah kemudian di edit dan di render lalu menghasilkan video yang siap untuk digunakan. Tampilan video yang di hasilkanpun akan lebih menarik dan tidak membosankan. Dengan adanya perencanaan visual semua tahapan akan terlaksana dengan baik dan akurat.

d. Perencanaan Broadcasting di tujukan untuk menjangkau masyarakat dengan program pendistribusian efektif serta efisien. Dengan di buatnya perencanaan broadcasting tujuan untuk mencakup masyarakat luas dengan memberikan informasi yang berkaitan dengan media video infografis ini agar mencapai target jangkauan penyebaran informasi yang diberikan. Sehingga dengan dibuatnya perencanaan broadcasting suatu media informasi atau media promosi menjadi arahan untuk dapat mencapai target jangkauan audience. 


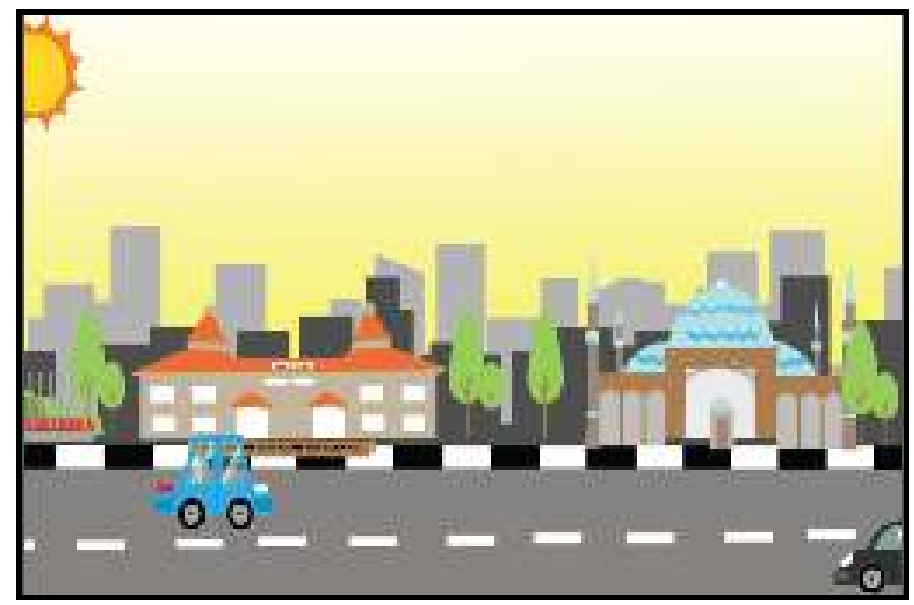

Gambar 13

Scene 1 Menampilkan suasana Kota Tangerang

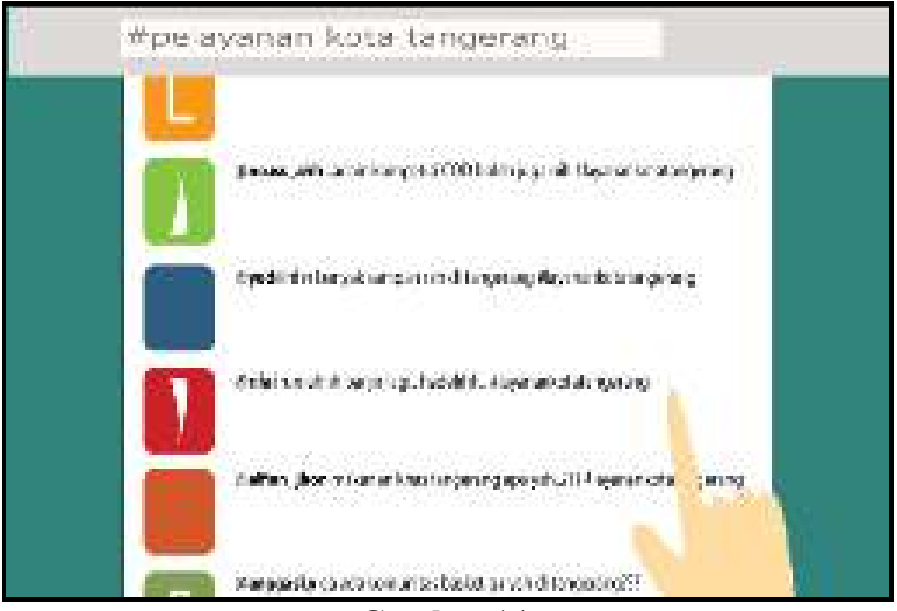

Gambar 14.

Scene 2 Menampilkan Contoh Media Sosial

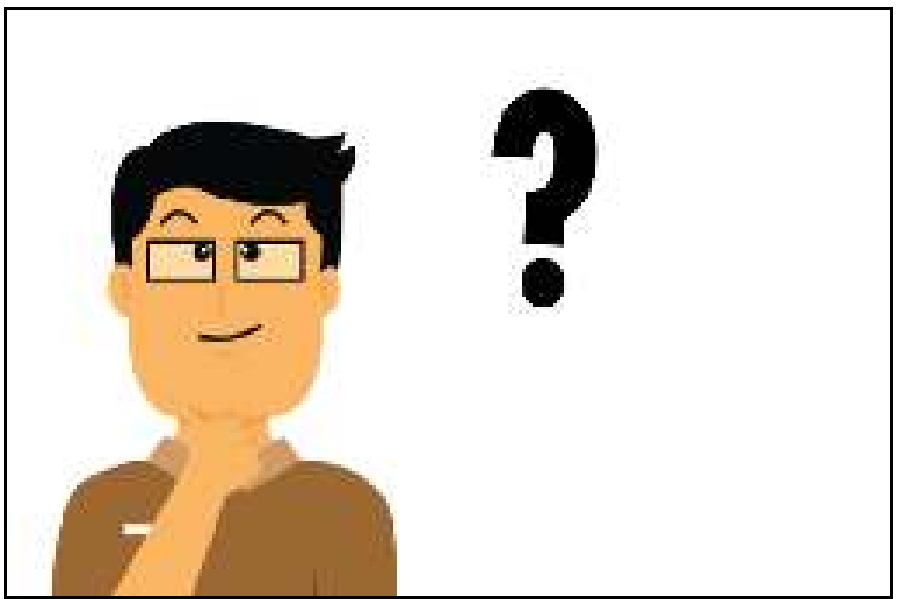

Gambar 15.

Scene 3 Menampilkan pegawai PNS yang sedang berfikir 


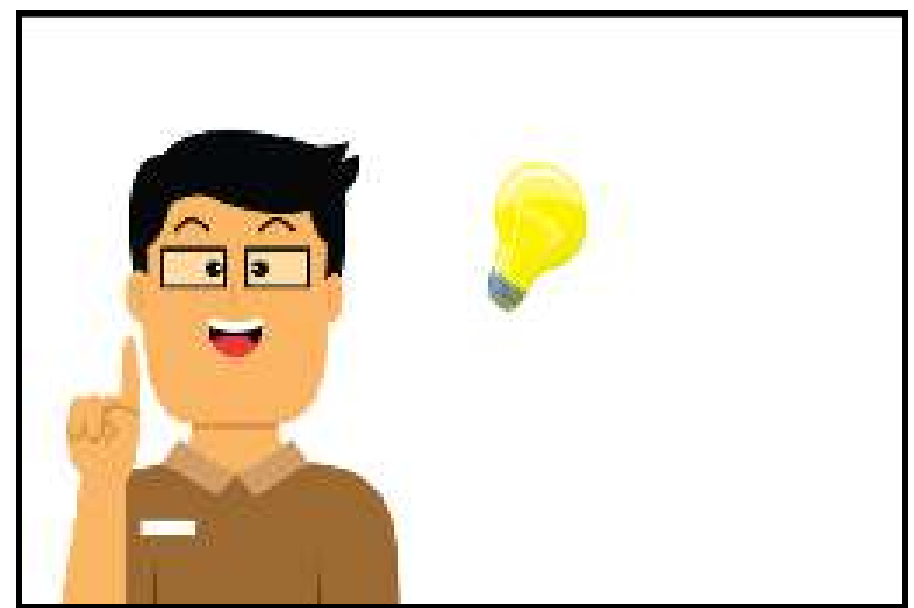

Gambar 16.

Scene 4 Menampilkan pegawai PNS yang mendapatkan solusi

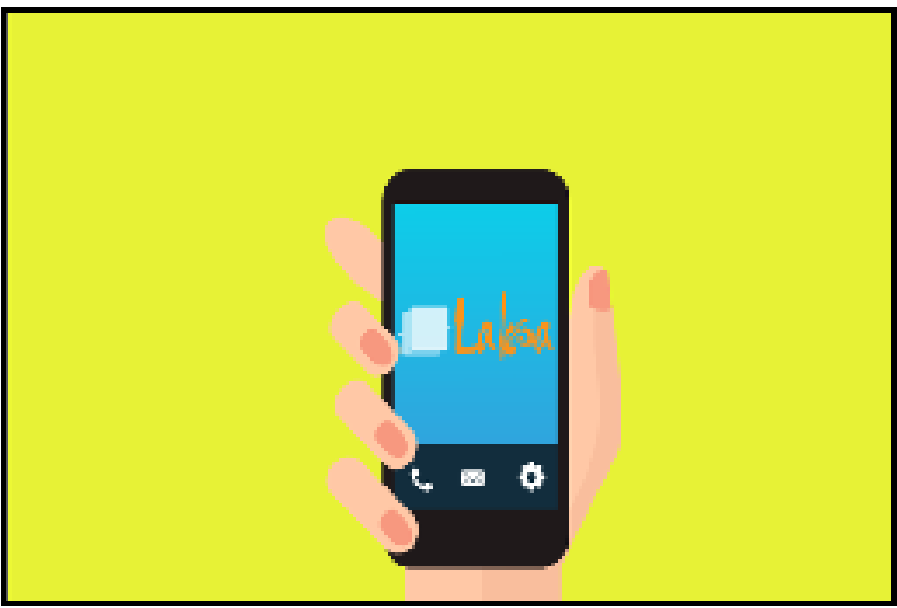

Gambar 17

Scene 5 Menampilakan logo aplikasi LAKSA melaui ponsel

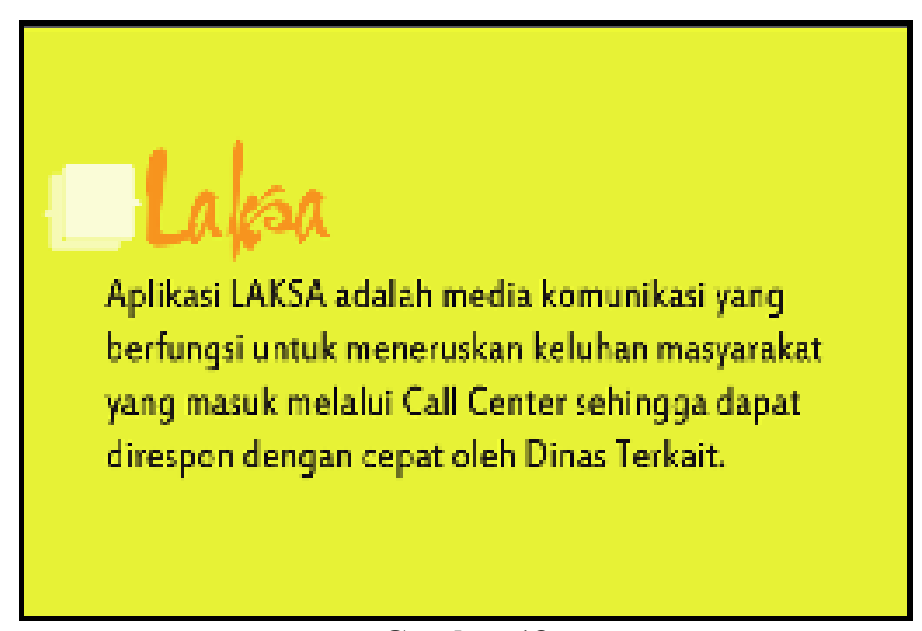

Gambar 18

Scene 6 Menampilkan dan menjelaskan layanan LAKSA 


\section{Bagaimana menggunakan aplikasi LAKSA?}

Gambar 19

Scene 7 Menampilkan menggunakan layanan LAKSA

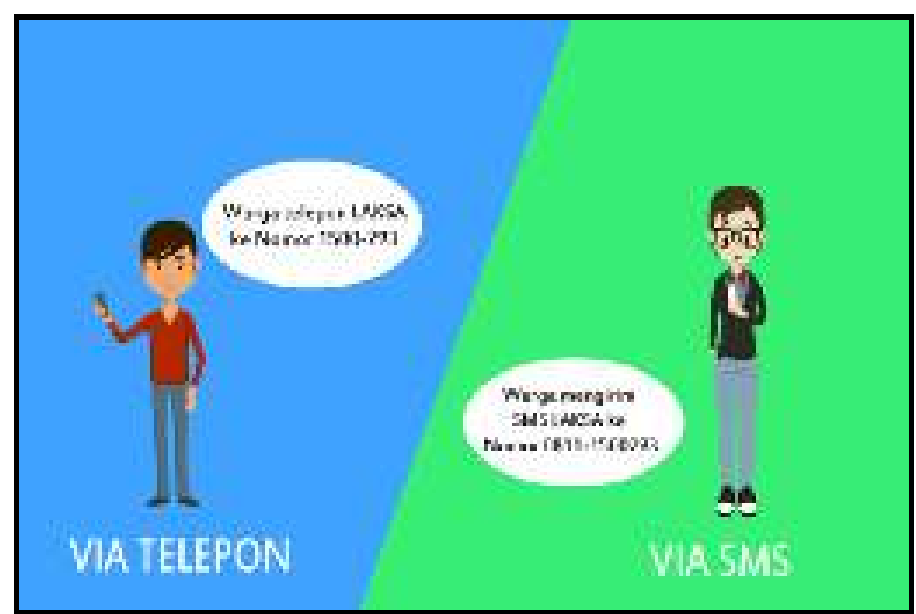

Gambar 20

Scene 8 (2 Cara menggunakan aplikasi LAKSA)

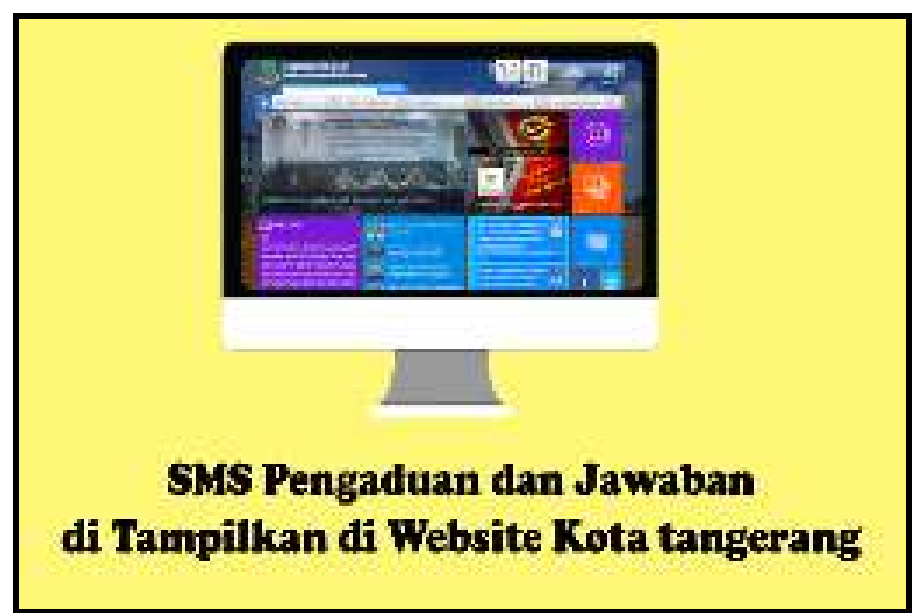

Gambar 21

Scene 9 SMS pengaduan di tampilkan di website 


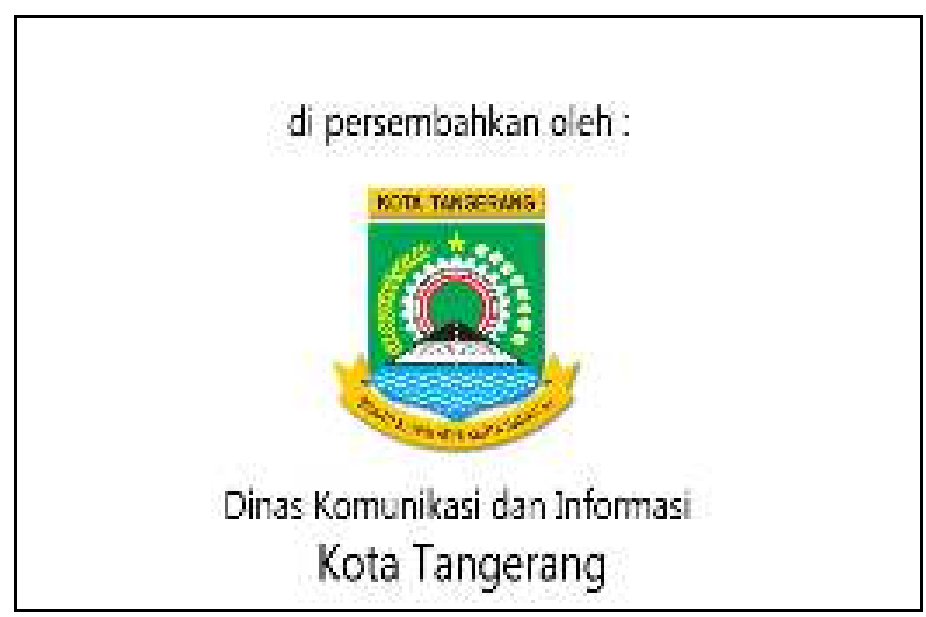

Gambar 22

Scene 10 Penutup

\section{Postproduction}

Postproduction adalah tahapan terakhir dari perancangan Konsep Produksi Media (KPM). Tahap postproduction adalah proses finishing sebuah karya sampai menjadi sebuah video yang utuh dan mampu menyampaikan sebuah cerita atau pesan kepada audience.

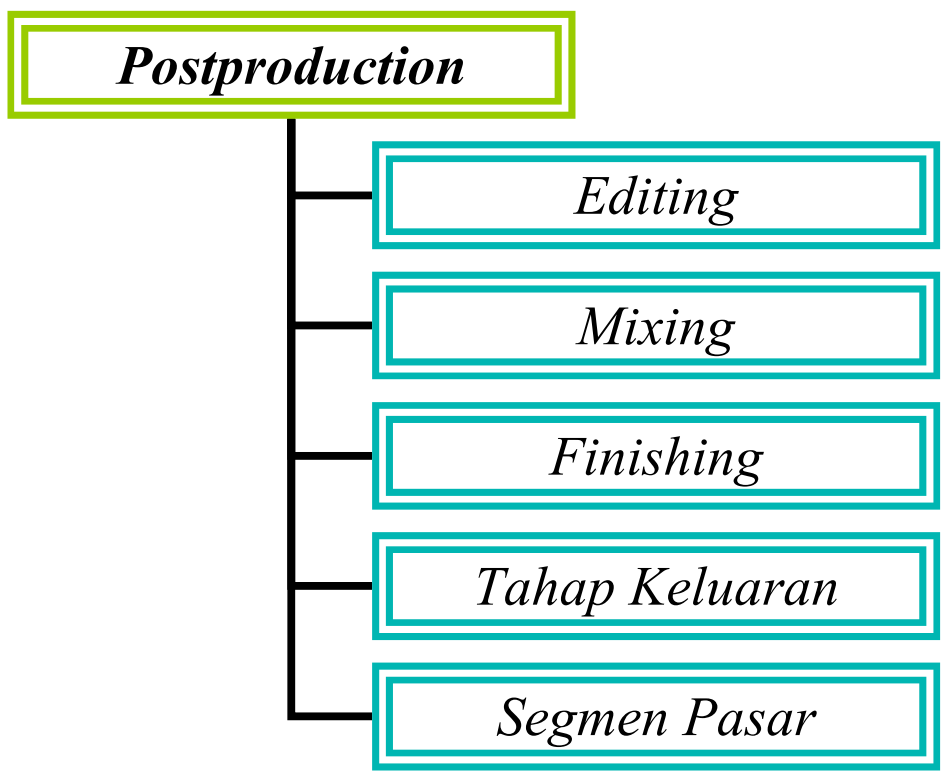

Gambar 23. Postproduction

\section{Kesimpulan}

Banyak sekali media untuk penyampaian informasi dan komunikasi, dan media video animasi infografis $2 \mathrm{D}$ adalah media yang paling efektif dari segi visual dan penyampaian informasi. Media video infografis dapat dijadikan sebagai penunjang informasi pada layanan aplikasi LAKSA (Layanan Aspirasi Kotak Saran Anda), sehingga masyarakat dengan mudah dapat memberikan pesan, keluhan, saran, ataupun laporan kepada Dinas terkait pada Pemerintahan Kota Tangerang. Dengan merancang video infografis aplikasi LAKSA dengan berbasis animasi 2D dimana terdapat unsur 
gerak, suara, musik,desain grafis, ilustrasi, dan warna yang menarik sehingga dapat menunjang aplikasi LAKSA yang mudah di pahami pemanfaatannya oleh masyarakat Kota Tangerang. Masyarakat dapat paham akan layanan aplikasi LAKSA dan dapat membantu memberikan pesan, keluhan, saran, ataupun laporan kepada Dinas terkait di

Kota Tangerang.

\section{Daftar Pustaka}

[1] Ayuningtyas, Melvy. 2010. "Ngedit Video Dengan Adobe Premiere CS3" Bekasi: Dunia Komputer.

[2] Binanto, Iwan. 2010. "Multimedia Digital (Dasar Teori dan Pengembangannya)", Yogyakarta: Andi

[3] Desrianti, Dewi Immaniar, Untung Rahardja, Reni Mulyani. 2012. Audio Visual As One Of The Teaching Resources On Ilearning. Journal CCIT Vol.5 No.2 - Januari 2012. Tangerang: Perguruan Tinggi Raharja

[4] Ikhwan August Star, Andry Alamsyah, dan Yahya "Perancangan Infografis Sebagai Alternatif Bentuk Nilai Mahasiswa (Studi Pada Mata Kuliah di Telkom University, Eksperimen: Mata Kuliah Entrepreneurship Prodi Adbis)" Bandung

[5] Indriasto, Doni "PERANCANGAN INFOGRAFIS BOARD GAME EDUKASI

SEJARANG PERANG SURABAYA 10 NOVEMBER 1945” Jawa Timur

[6] IDS / International Design School. "Pengertian Animasi dan Jenis Animasi" Diakses pada tanggal 13 Juni 2014. Dari link http ://www.idseducation.com/2014/06/13/apa-itu-animasi/

[7] Lankow, Jason, Jose Ritchie, Ross Croocks, "Infographics: Power of Visual Storrytelling” Hoboken, New Jersey: John Wiley \& Sons, Inc. 2012.

[8] Nugraha, Muhamd Riyan Surya "Perancangan Media Video Infografis Menggunakan Animasi 3D Max Di Klinik Usada Nugraha Kabupaten Tangerang" Tangerang: SKRIPSI STMIK Raharja

[9] Soepadmo, Gatoet. 2013, “Panduan Mudah Merancang Bangunan”. Niaga Swadaya, Jakarta.

[10] Website Kota Tangerang. "Apa itu LAKSA? Di akses pada tanggal 31 Oktober 2015. Dari link http://www.tangerangkota.go.id/laksa/faq

[11] Maimunah, Lusyani Sunarya, Nina Larasati. 2012. Media Company Profile Sebagai Sarana Penunjang Informasi dan Promosi. Journal CCIT Vol.5 No.3 - Mei 2012. Tangerang: Perguruan Tinggi Raharja.

[12] Mulyate, Karenia Marisa "Perancangan Buku Kumpulan Infografis Resep Aneka Hidangan Pembuka dan Penutup Ala Barat Untuk AnakAnak" Surabaya

[13] TW, Ibnu. 2013. Belajar desain grafis. Yogyakarta: Media Pressindo

[14] Hendratman, Hendi, ST. 2010."Tips n Trix Computer Graphics Design", Informatika Bandung. 